\title{
Analyzing the Behavioral Changes of Road User through Euclidean Distance Intuitionistic Fuzzy Valued Associative Memories
}

\author{
A. Victor Devadoss \\ Department of Mathematics, Loyola \\ College, Chennai-34, Tamil Nadu, India
}

\author{
S.M.A. Shahul Hameed \\ Department of Mathematics, Aalim \\ MuhammedSalegh College of Engineering, India
}

\begin{abstract}
Driving Safely is a primary issue in all developing countries around the world. It alarms towards drivers attitude and behavior changes towards road safety. The main objective of this paper is to introduce a new multi expert fuzzy model called Euclidean Distance Intuitionistic Fuzzy Valued Associative Memories (EDIFVAM) . In this paper we analyze the correlation between the causes and effects of human health problems and human errors on roads that makes destruction on road safety was illustrated using EDIFVAM.The paper was constituted into five section with introduction to the problem, preliminaries to intuitionistics fuzzy sets and fuzzy associative memories, introduction to EDIFVAM ,adaptation of problem to EDIFVAM , and conclusion and suggestion based on the study.
\end{abstract}

\section{Keywords}

Intuitionistic fuzzy values, Associative memories ,Road safety, Human health problems ,Human errors and EDIFVAM

\section{INTRODUCTION}

The road crashes are caused by poor human behavior and that the causes are dominated by premeditated mistakes, such as violations and traffic offences. Studies predicts that in almost all crashes the human being are to be blamed, and only a marginal of crashes can be attributed to road environment and poor performance of vehicles. In today's modern world, everybody is always surrounded by uncertainties immaterial about the age group in which they belong. A man starts from his house, no surety that he will return home safely. People become victim of others irresponsible behavior on the roads. The indiscipline behavior of road user creates kayos in the road. People unwilling to follow the road rules while driving, the negligence of pedestrians while crossing, parking the vehicles in the no parking areas, encroachment of roads, speeding in the wrong places and the traffic police not maintain the law and order are some of the issues everyone facing and contributing negatively for others safety. Many of the fatal accident are happening on the roads due to irresponsible behavior of other persons.

The economic development of an country mainly depends on the transport system. The main objective of any public transport system is to provide an efficient, safe and economical system to move from one place to another place. The number of road casualties per jurisdiction in a certain period of time (a couple of years for example) is changing. In a substantial numberof countries an increase has been observed, whereas some other countries show a decrease. The Global Status report (WHO, 2013) presented a decline in 88 countries; 42 of which were high income countries, 41 were middle-income countries, and 5 were low income countries. But the same report indicated an increase in the number of fatalities in 87 countries. Sometimes it is stated that an increase in economic growth, resulting in increased motorisation and an increase in kilometers travelled, will inevitably result in an increase in the number of road casualties.

To understand the causes of a crash are not easy to find. In the past, we relied on police information which was written down in crash report forms. These forms focused on violations, in order to assist in police activities, as they are supposed to do. In the majority of crashes, more than one cause plays a role. The human being failed in one way or another.

\section{INTUITIONISTIC FUZZY SETS AND FUZZY ASSOCIATIVE MEMORIES}

\subsection{Preliminaries:}

\section{Definition: 2.1.1}

If $X$ is a collection of objects denoted generically by $\mathrm{x}$ then a fuzzy set $\mathrm{A}$ in $\mathrm{X}$ is a set of ordered pairs

$$
A^{\prime}=\left\{\left(x, \mu_{A^{\prime}}(x)\right) / x \in X\right\} \text { where } \mu_{A^{\prime}}(x) \text { is }
$$
called membership function or grade of membership of $\mathrm{x}$ in $A^{\prime}$

Definition 2.1.2

The Atanassov intuitionistics fuzzy set (A-IFS) for A is given by $A=\left\{\left(x, \mu_{A}(x), v_{A}(x)\right) / x \in X\right\}$ where

$\mu_{A}(x): X \rightarrow[0,1]$ and $v_{A}(x): X \rightarrow[0,1]$ such that

$0 \leq \mu_{A}(x)+v_{A}(x) \leq 1$ and $\mu_{A}(x), v_{A}(x) \in[0,1]$ denote a degree of membership and a degree of non membership of $x \in A$, respectively.

Definition 2.1.3

The hesitation margin of an intuitionistic fuzzy index of $x \in A$, is given by $\pi_{A}(x)=1-\mu_{A}(x)-v_{A}(x)$ clearly $0 \leq \pi_{A}(x) \leq 1$ for each $x \in X$, on other hand it is define as triplet containing a $A=\left\{\left(x, \mu_{A}(x), \pi_{A}(x), v_{A}(x)\right) / x \in X\right\}$ as membership, hestitation degree and non membership values of a set.

\section{Definition : 2.1.4}

The distance for fuzzy sets A, B in $X=\left\{x_{1}, x_{2}, \ldots \ldots x_{n}\right\}$ are Hamming distance $\mathrm{d}(\mathrm{A}, \mathrm{B})$ :

$d(A, B)=\sum_{i=1}^{n}\left|\mu_{A}\left(x_{i}\right)-\mu_{B}\left(x_{i}\right)\right|$ 
Euclidean distance $\mathrm{e}(\mathrm{A}, \mathrm{B})$ :

$$
e(A, B)=\sqrt{\sum_{i=1}^{n}\left(\mu_{A}\left(x_{i}\right)-\mu_{B}\left(x_{i}\right)\right)^{2}}
$$

It is for fuzzy set consists only membership function.

\section{Definition : 2.1.5}

The equivalent representation of distance in intuitionistic fuzzy set value is $A=\left\{\left(x, \mu_{A}(x), v_{A}(x)\right) / x \in X\right\}$

Hamming distance $d_{I F S}(A, B)$ :

$d_{I F S}(A, B)=\frac{1}{2} \sum_{i=1}^{n}\left(\mu_{A}\left(x_{i}\right)-\mu_{B}\left(x_{i}\right)\right)+\left(v_{A}\left(x_{i}\right)-v_{B}\left(x_{i}\right)\right)+\left(\pi_{A}\left(x_{i}\right)-\pi_{B}\left(x_{i}\right)\right)$

Euclidean distance e(A,B):

$e_{I F S}(A, B)=\sqrt{\frac{1}{2} \sum_{i=1}^{n}\left(\mu_{A}\left(x_{i}\right)-\mu_{B}\left(x_{i}\right)\right)^{2}+\left(v_{A}\left(x_{i}\right)-v_{B}\left(x_{i}\right)\right)^{2}+\left(\pi_{A}\left(x_{i}\right)-\pi_{B}\left(x_{i}\right)\right)^{2}}$

Where $\pi_{A}(x)$ is the hesitation margin represented as

$\pi_{A}(x)=1-\mu_{A}(x)-v_{A}(x)$

\subsubsection{Fuzzy Associative Memories}

With the view of geometric representation, a fuzzy set is a point in a unit hypercube, a non-fuzzy set is a vertex of the cube and a fuzzy system as a mapping between hypercubes. A fuzzy system $\mathrm{S}$ is a transformation $S: I^{n} \rightarrow I^{p}$ The ndimensional unit hypercube $I^{n}$ houses of all fuzzy subsets of the domain space with $X=\left\{x_{1}, x_{2}, \ldots x_{n}\right\}, I^{p}$ as houses of all fuzzy subsets of the range space with $Y=\left\{y_{1}, y_{2}, . . y_{n}\right\}$. In general a fuzzy system $\mathrm{S}$ maps families of fuzzy sets to families of fuzzy sets, thus $S: I^{n} \times I^{n} \times I^{n} \mathrm{~K} I^{n} \rightarrow I^{p} \times I^{p} \times I^{p} \mathrm{~K} I^{p}$ we shall also focus on fuzzy system $S: I^{n} \rightarrow I^{p}$ that map balls of fuzzy sets in $I^{n}$ to balls of fuzzy sets in $I^{p}$. They map close inputs to close outputs. These are referred as fuzzy associative memories also know as FAMs.

The simplest FAM encodes the FAM rule or association $\left(\mathrm{A}_{\mathrm{i}}\right.$, $B_{i}$ ) which associates $p$-dimensional fuzzy set $B_{i}$, with the $n$ dimensional fuzzy set $A_{i}$. Theses minimal FAMs essentially map one ball in $I^{n}$ to one ball in $I^{p}$. They are comparable to simple neural networks. Each input A to the FAM system activates each stored FAM rule to different degree. The minimal FAM that stores $\left(\mathrm{A}_{\mathrm{i}}, \mathrm{B}_{\mathrm{i}}\right)$ maps input $\mathrm{A}$ to $B_{i}^{\prime}$, a partially activated version of $B_{i}$. The more $A$ resembles $A_{i}$, the more $\mathrm{B}_{\mathrm{i}}$ resembles $B_{i}^{\prime}$. The corresponding output fuzzy set $\mathrm{B}$ combines these partially activated fuzzy sets $B_{1}^{\prime}, B_{2}^{\prime}, B_{3}^{\prime}, \mathrm{K} B_{n}^{\prime}$, B equalsa weighted average of the partially activated sets.

$B=w_{1} B_{1}^{\prime}+w_{2} B_{2}^{\prime}+, w_{3} B_{3}^{\prime}+, \mathrm{K} w_{n} B_{n}^{\prime}$, Where $\mathrm{w}_{\mathrm{i}}$ reflects the credibility, frequency or strength of the fuzzy association
$\left(A_{i}, B_{i}\right)$ which when defuzzified to the output waveform $B$ to single numerical value, $y_{j}$ in $Y$. by computing the fuzzy centroid of $\mathrm{B}$ with respect to the output universe of discourse Y.

Definition: 2.1.7

If the equilibrium state of a dynamical system is a unique state vector, then it is called a fixed point

Definition: 2.1.8

If the FAM settles with a state vector repeating in the form $A_{1} \rightarrow A_{2} \rightarrow A_{3} \rightarrow \mathrm{K} \rightarrow A_{i} \rightarrow A_{1}$ then this equilibrium is called a limit cycle of the FAM.

\section{EUCLEDIAN DISTANCE INTUITIONISTIC FUZZY VALUED ASSOCIATIVE MEMORIES ( EDIFVAM)}

Let ${ }_{\mathrm{IF}} \mathrm{ED}_{\mathrm{A} 1},{ }_{\mathrm{IF}} \mathrm{ED}_{\mathrm{A} 2},{ }_{\mathrm{IF}} \mathrm{ED}_{\mathrm{A} 3} \cdots{ }_{\mathrm{IF}} \mathrm{ED}_{\mathrm{Am}}$ and ${ }_{\mathrm{IF}} \mathrm{ED}_{\mathrm{G} 1,{ }_{\mathrm{IF}}} \mathrm{ED}_{\mathrm{G} 2}$, ${ }_{\mathrm{IF}} \mathrm{ED}_{\mathrm{G} 3} \ldots \mathrm{IF}_{\mathrm{IF}} \mathrm{ED}_{\mathrm{Gn}}$ be the antecedent $\mathrm{F}_{\mathrm{x}}$ and the consequent $\mathrm{F}_{\mathrm{y}}$ nodes of the EDIFVAM respectively. The relation between these nodes in different scale of intuitonistic fuzzy values ranges from $[0,1]$ linguistic in nature are defined in the form of adjacency matrix having causal relationship between neurons of Fx with neurons of Fy by opinion of k-experts is represented as $v_{1}=\left(a_{i j}{ }^{1}\right), v_{2}=\left(a_{i j}{ }^{2}\right) \ldots v_{k}=\left(a_{i j}{ }^{K}\right)$ for $\mathrm{i}=1,2, \ldots m$ and $j=1,2, \ldots n$. Each expert opinion described in the form of a matrix

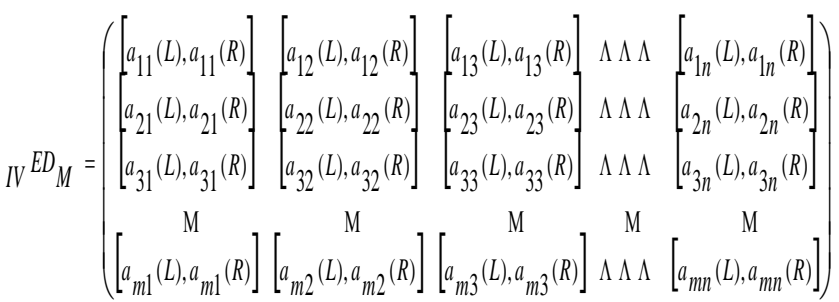

where $a_{i j}(L)$ and $a_{i j}(R)$ are the (Left Spread) membership and (Right Spread) non-membership of intuitionistic fuzzy set valued functionThen these matrix are combined into synaptic connection matrix

$$
\begin{aligned}
& \mathrm{A}_{\mathrm{ij}}(\mathrm{L}, \mathrm{R})=\left\{\max _{1 \leq \mathrm{i} \leq \mathrm{m}}\left(\mathrm{a}_{\mathrm{ij}}(\mathrm{L})\right), \min _{1 \leq \mathrm{i} \leq \mathrm{m}} \mathrm{a}_{\mathrm{ij}}(\mathrm{R})\right\} \\
& B_{i j}(L, R)=\left\{\min _{1 \leq i \leq m}\left(\mathrm{a}_{\mathrm{ij}}(\mathrm{L})\right), \max _{1 \leq \mathrm{i} \leq \mathrm{m}} \mathrm{a}_{\mathrm{ij}}(\mathrm{R})\right\} \quad \mathrm{j}=1,2, \ldots \ldots \mathrm{n}, \ldots
\end{aligned}
$$

whose value are also intuitionistic fuzzy values. We further reduce this matrix into one connection synaptic matrix by defining euclidean hamming distance

$$
\begin{aligned}
& I V E D_{D}=\sqrt{\frac{1}{2} \sum_{j=1}^{n} \sum_{i=1}^{m}\left(A_{i j}(L)-B_{i j}(L)\right)^{2}+\left(\left(A_{i j}(R)-B_{i j}(R)\right)^{2}+\left(\left(H_{i j}(A)-H_{i j}(B)\right)^{2}\right.\right.} \\
& \ldots \text { (2) where } \quad H_{i j}(A)=1-\max _{1 \leq i \leq m}\left(\mathrm{a}_{\mathrm{ij}}(\mathrm{L})\right)-\min _{1 \leq i \leq \mathrm{m}} \mathrm{a}_{\mathrm{ij}}(\mathrm{R}) \quad \text { and } \\
& H_{i j}(B)=1-\min _{1 \leq i \leq m}\left(\mathrm{a}_{\mathrm{ij}}(\mathrm{L})\right)-\max _{1 \leq \mathrm{i} \leq \mathrm{m}} \mathrm{a}_{\mathrm{ij}}(\mathrm{R}) \quad \ldots \ldots(3) \mathrm{j}=1,2, \ldots \ldots \mathrm{n} .
\end{aligned}
$$

represented as ${ }_{I V} E D_{D}$ 


\subsection{Method Of Determining the Hidden Pattern for Eucledian Distance Intuitionistic Fuzzy Valued Associative Memories (EDIFVAM)}

Step:1:

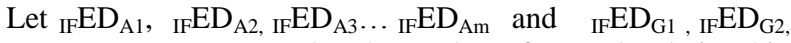
${ }_{\mathrm{IF}} \mathrm{ED}_{\mathrm{G} 3} \ldots . .{ }_{\mathrm{IF}} \mathrm{ED}_{\mathrm{Gn}}$ be the nodes of causal relationship between causes and effects of associated adjacency matrix denoted by $\left({ }_{{ }_{I v}} \mathrm{ED}_{\mathrm{M}}\right)$ respectively.

Step:2:

By applying the above equation (1) ,(2) and (3) the adjacency distance matrix ${ }_{I V} E D_{D}$ is constructed.

Step:3:

Let us find the hidden pattern $X_{1}$ be the initial state input vector of order $1 \mathrm{x} \mathrm{n}$. A particular state of the component vector to be On state by making it as 1 and remaining states are kept at Off state by 0.Initially we make the first component to be On state as 1 and remaining states to 0 represented as $X_{1}=\{1,0,0,0, \ldots, 0\}$ The initial state vector is then passed through the connection distance matrix ${ }_{I V} E D_{D}$.

Step:4:

To convert the resultant vector into a signal function,the initial state vector is passed on through the relational connection distance matrix $I_{V} E D_{D}$ that is by multiplying $\mathrm{X}_{1}\left({ }_{I V} E D_{D}\right)$ the resultant vector is thresholded (defuzzifying) by choosing the first two highest value of the component to be On state and the rest of values are to be kept at Off state by 1 and 0 respectively

Step:5:

The resultant row vector $\mathrm{X}_{1}\left({ }_{\mathrm{Iv}} \mathrm{ED}_{\mathrm{D}}\right)=\left\{a_{1}, a_{2}, \ldots \ldots a_{n}\right\}$ is then multiplied with the transpose of the matrix $\left({ }_{\mathrm{IV}} \mathrm{ED}_{\mathrm{D}}\right)^{T}$ and it is also thresholded by choosing the first two highest value of the component to be On state as 1 and rest of the values are to kept at Off state as 0 . Repeated thresholding yields a new state vector $X_{2}$ and goes on.

Step:6:

Repeat this process from step 3 to 5 until equilibrium state of limit cycle or fixed point for the dynamical system is reached.

Step:7:

Valid inference will be reached from the limit cycle of dynamical system.

\section{Adaptation of Problem to EDIFVAM}

We have adapted this model Euclidean Intuitionistic Fuzzy Valued Associative Memories (EDIFVAM) as a multi expert model, it is more suitable to study the influence of Human Health problem and Human Errors on roads as two disjoint classes. Around hundred road users from different part of Chennai are interviewed whose valuable opinions are collected and recorded .Among the linguistic variable ,suitable attributes are taken for this study is divided into two disjoint classes.

Table 1: Attributes related to Human Health Problem on roads as the nodes of domain space

\begin{tabular}{|c|c|}
\hline \multicolumn{2}{|c|}{ Attribute } \\
\hline A1 & Sleep Deprivation \\
\hline A2 & Addicted To Drugs /Alcohol \\
\hline A3 & Drowsiness / Tiredness \\
\hline A4 & Stress /Tension \\
\hline A5 & Body Pain /Headache \\
\hline A6 & Poor Eye Vision \\
\hline
\end{tabular}

Table 2: Attributed related to Human Errors on roads as range space

\begin{tabular}{|c|c|}
\hline \multicolumn{2}{|c|}{ Attribute } \\
\hline G1 & Difficult in Focusing \\
\hline G2 & Ylinking Eyes Frequently \\
\hline G3 & Delay in Reaction \\
\hline G4 & Poor Judgement \\
\hline G5 & Drifting from Lane to Lane \\
\hline G6 & Feeling Irritated \\
\hline G7 & \\
\hline
\end{tabular}

The relational connection matrix given by the first expert

$V_{1}=\left(\begin{array}{lllllll}{[0.6,0.4]} & {[0.5,0.2]} & {[0.5,0.4]} & {[0.4,0.4]} & {[0.3,0.3]} & {[0.7,0.3]} & {[0.3,0.2]} \\ {[0.4,0.3]} & {[0.4,0.2]} & {[0.4,0.1]} & {[0.3,0.1]} & {[0.4,0.2]} & {[0.5,0.2]} & {[0.5,0.3]} \\ {[0.6,0.2]} & {[0.6,0.1]} & {[0.8,0.1]} & {[0.7,0.2]} & {[0.7,0.3]} & {[0.6,0.2]} & {[0.8,0.1]} \\ {[0.6,0.3]} & {[0.7,0.2]} & {[0.6,0.3]} & {[0.7,0.3]} & {[0.4,0.2]} & {[0.8,0.1]} & {[0.6,0.2]} \\ {[0.7,0.3]} & {[0.5,0.3]} & {[0.7,0.2]} & {[0.6,0.2]} & {[0.5,0.3]} & {[0.5,0.2]} & {[0.4,0.3]} \\ {[0.5,0.1]} & {[0.7,0.2]} & {[0.8,0.2]} & {[0.7,0.2]} & {[0.5,0.3]} & {[0.6,0.1]} & {[0.5,0.2]}\end{array}\right)$

The relational connection matrix given by the second expert

$$
v_{2}=\left(\begin{array}{lllllll}
{[0.6,0.4} & {[0.7,0.2]} & {[0.8,0.1]} & {[0.6,0.4]} & {[0.6,0.1]} & {[0.2,0.2]} & {[0.5,0.1]} \\
{[0.7,0.1]} & {[0.3,0.2]} & {[0.2,0.3]} & {[0.8,0.2]} & {[0.7,0.2]} & {[0.2,0.3]} & {[0.6,0.1]} \\
{[0.8,0.1]} & {[0.5,0.1]} & {[0.5,0.4]} & {[0.7,0.2]} & {[0.7,0.3]} & {[0.3,0.1]} & {[0.5,0.3]} \\
{[0.6,0.2]} & {[0.2,0.5]} & {[0.2,0.3]} & {[0.5,0.2]} & {[0.6,0.3]} & {[0.8,0.2]} & {[0.7,0.2]} \\
{[0.7,0.1]} & {[0.2,0.3]} & {[0.2,0.2]} & {[0.5,0.5]} & {[0.5,0.5]} & {[0.3,0.2]} & {[0.5,0.5]} \\
{[0.8,0.1]} & {[0.6,0.1]} & {[0.2,0.3]} & {[0.6,0.2]} & {[0.7,0.3]} & {[0.5,0.1]} & {[0.2,0.1]}
\end{array}\right)
$$

The relational connection matrix given by the third expert

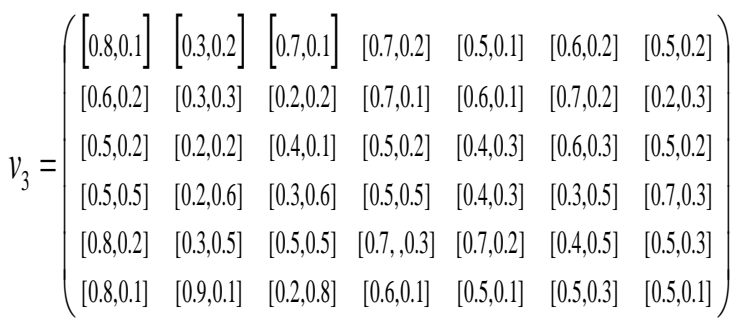

Relational Matrix with $\{$ Max,Min $\}$ with intuitionistic values 
$A(L, R)=\left(\begin{array}{lllllll}{[0.8,0.1]} & {[0.7,0.2]} & {[0.8,0.1]} & {[0.7,0.2]} & {[0.6,0.1]} & {[0.7,0.2]} & {[0.5,0.1]} \\ {[0.7,0.1]} & {[0.4,0.2]} & {[0.4,0.3]} & {[0.8,0.2]} & {[0.7,0.2]} & {[0.7,0.3]} & {[0.6,0.1]} \\ {[0.8,0.1]} & {[0.6,0.1]} & {[0.8,0.1]} & {[0.7,0.2]} & {[0.7,0.3]} & {[0.6,0.1]} & {[0.8,0.1]} \\ {[0.6,0.2]} & {[0.7,0.2]} & {[0.6,0.3]} & {[0.7,0.2]} & {[0.6,0.2]} & {[0.8,0.1]} & {[0.7,0.2]} \\ {[0.8,0.1]} & {[0.5,0.3]} & {[0.7,0.2]} & {[0.7,0.2]} & {[0.7,0.2]} & {[0.5,0.2]} & {[0.5,0.3]} \\ {[0.8,0.1]} & {[0.9,0.1]} & {[0.8,0.2]} & {[0.7,0.1]} & {[0.7,0.1]} & {[0.6,0.1]} & {[0.5,0.1]}\end{array}\right)$

Relational Matrix with $\{$ Min,Max $\}$ intuitionistic values

$$
B(L, R)=\left(\begin{array}{lllllll}
{[0.6,0.4]} & {[0.3,0.2]} & {[0.5,0.4]} & {[0.4,0.4]} & {[0.3,0.3]} & {[0.2,0.3]} & {[0.3,0.2]} \\
{[0.4,0.3]} & {[0.3,0.3]} & {[0.2,0.3]} & {[0.3,0.2]} & {[0.4,0.2]} & {[0.2,0.3]} & {[0.2,0.3]} \\
{[0.5,0.2]} & {[0.2,0.2]} & {[0.4,0.4]} & {[0.5,0.2]} & {[0.4,0.3]} & {[0.3,0.3]} & {[0.5,0.3]} \\
{[0.5,0.5]} & {[0.2,0.6]} & {[0.2,0.6]} & {[0.5,0.5]} & {[0.4,0.3]} & {[0.3,0.5]} & {[0.6,0.3]} \\
{[0.7,0.3]} & {[0.2,0.5]} & {[0.2,0.5]} & {[0.5,0.5]} & {[0.5,0.5]} & {[0.3,0.5]} & {[0.4,0.5]} \\
{[0.5,0.1]} & {[0.6,0.2]} & {[0.2,0.8]} & {[0.6,0.2]} & {[0.5,0.3]} & {[0.5,0.3]} & {[0.2,0.2]}
\end{array}\right)
$$

Matrix with Euclidean Distance for Intuitionistic fuzzy along with hesitation values

$$
{ }_{I} E D_{D}=\left(\begin{array}{ccccccc}
0.187 & 0.283 & 0.212 & 0.187 & 0.187 & 0.324 & 0.122 \\
0.187 & 0.071 & 0.141 & 0.324 & 0.187 & 0.324 & 0.245 \\
0.187 & 0.255 & 0.255 & 0.141 & 0.212 & 0.187 & 0.187 \\
0.187 & 0.324 & 0.255 & 0.187 & 0.122 & 0.324 & 0.071 \\
0.122 & 0.187 & 0.308 & 0.187 & 0.187 & 0.187 & 0.122 \\
0.212 & 0.187 & 0.424 & 0.071 & 0.141 & 0.122 & 0.187
\end{array}\right)
$$

Let us consider $\mathrm{X} 1=\left(\begin{array}{llllll}1 & 0 & 0 & 0 & 0 & 0\end{array}\right)$

$$
\begin{aligned}
& \mathrm{X} 1\left({ }_{\mathrm{IV}} \mathrm{ED}_{\mathrm{D}}\right)=(0.187,0.283,0.212,0.187,0.187,0.324,0.122) \\
& \hookrightarrow\left(\begin{array}{lllllll}
0 & 1 & 0 & 0 & 0 & 1 & 0
\end{array}\right)=\mathrm{Y} 1 \\
& \mathrm{Y} 1\left({ }_{\mathrm{IV}} \mathrm{ED}_{\mathrm{D}}\right)^{\mathrm{T}}=(0.606,0.395,0.442,0.648,0.374,0.309)
\end{aligned}
$$

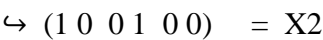

$$
\begin{aligned}
& \mathrm{X} 2\left({ }_{\mathrm{IV}} \mathrm{ED}_{\mathrm{D}}\right)=(0.374,0.607,0.467,0.374,0.309,0.648,0.193)
\end{aligned}
$$

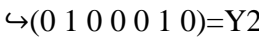

\begin{tabular}{|c|c|}
\hline Input Vector & Limit Points \\
\hline 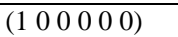 & 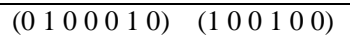 \\
\hline$\left(\begin{array}{llllllll}0 & 1 & 0 & 0 & 0 & 0\end{array}\right)$ & $\left.\begin{array}{lllllllllll}0 & 0 & 0 & 1 & 0 & 1 & 0\end{array}\right) \quad\left(\begin{array}{llllll}1 & 1 & 0 & 1 & 0 & 0\end{array}\right)$ \\
\hline 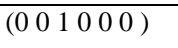 & $\left.\begin{array}{lllllll}0 & 1 & 1 & 0 & 0 & 0\end{array}\right) \quad\left(\begin{array}{llllll}0 & 0 & 0 & 1 & 0 & 1\end{array}\right)$ \\
\hline$\left(\begin{array}{lllllll}0 & 0 & 0 & 1 & 0 & 0\end{array}\right)$ & $\left.\begin{array}{llllllllllll}0 & 1 & 0 & 0 & 1 & 0 & 0\end{array}\right)\left(\begin{array}{lllllll}1 & 0 & 0 & 1 & 0 & 0\end{array}\right)$ \\
\hline$\left(\begin{array}{lllllll}0 & 0 & 0 & 0 & 1 & 0\end{array}\right)$ & $\left.\begin{array}{llllllllllll}0 & 1 & 0 & 0 & 1 & 0 & 0\end{array}\right)\left(\begin{array}{lllllll}1 & 0 & 0 & 1 & 0 & 0\end{array}\right)$ \\
\hline$\left(\begin{array}{lllllll}0 & 0 & 0 & 0 & 0 & 1\end{array}\right)$ & $\left(\begin{array}{lllllll}0 & 1 & 1 & 0 & 0 & 0 & 0\end{array}\right) \quad\left(\begin{array}{llllll}0 & 0 & 0 & 1 & 0 & 1\end{array}\right)$ \\
\hline
\end{tabular}

$$
\begin{aligned}
& \mathrm{Y} 2\left({ }_{\mathrm{IV}} \mathrm{ED}_{\mathrm{D}}\right)^{\mathrm{T}}=(0.606,0.395,0.442,0.648,0.374,0.309) \\
& \hookrightarrow\left(\begin{array}{llllll}
1 & 0 & 0 & 1 & 0 & 0
\end{array}\right)=\mathrm{X} 3=\mathrm{X} 2
\end{aligned}
$$

Hence the pair of limit point is

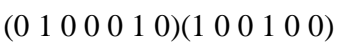

Table 3 : Limit points for various set of initial input vectors

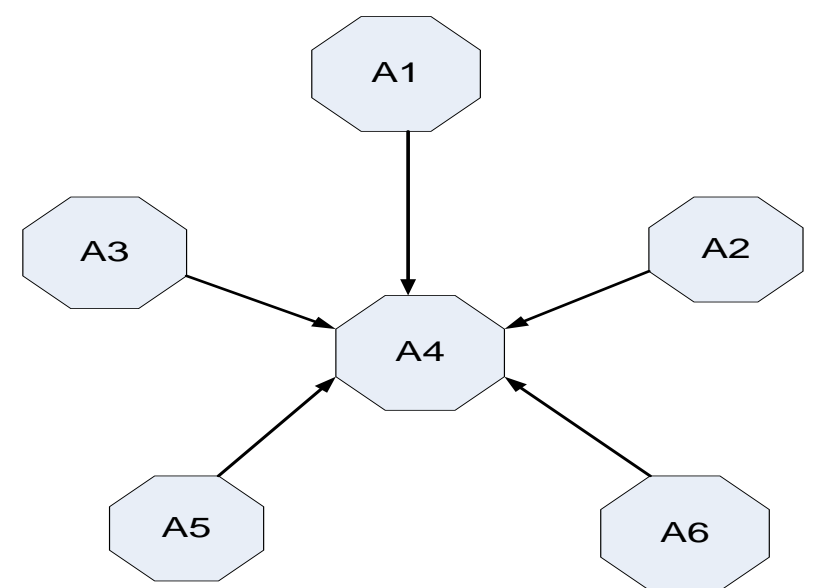

Fig:1: Triggering Pattern of Associative Memories

\section{CONCLUSION AND SUGGESTION}

The study clearly predicts that as when A1 (Sleep Deprivation) is On state provokes frequent blinking of eyes(G2) and drifiting from lane to lane (G6) as a resultant stress and tension(A4) gets on On state is the major contributory behavior of road user to be involved in dreadful accidents on roads .As when we proceed on with different initial state as A2,... A6 to be On state the most influential among the state is stress and tension (A4) act as a triggering pattern for all the causes and predominant human vulnerable behavior towards roads. Further addicted to drugs or alcohol, tiredness, poor eye vision plays a contributory role to road collision by provoking difficulty in eye focusing, yawning repeatedly, delay in reaction and poor judgments by Human.

The following awareness measures are to be followed

a) To Develop economic status of any country, the measure of awareness with education to road safety and prevention from road death with serious injuries

b) It should focuses on safer and reduced speeds along with air pollution and energy consumption.

c) Consequent measure to reduce the growing number of vehicles on roads

d) Drivers with awareness of road safety

e) Enforce most efficient license procedure to train the drivers

f) Ensure effective enforcement to check violation of basic safety requirements drunken driving and implement deterrent penal provision.

6. References

[1] Axelrod. R. 1976. Structure of decision. The cognitive maps of politicalelites. Princeton University.

[2] K. Atanassov, Intuitionistic fuzzy sets, Fuzzy Sets and Systems 20 (1986) 87-96

[3] BartKosko. 2003. Neural Networks and Fuzzy System prentice .Hall of India private Limited. New Delhi 110001 
[4] Klir, G.J. and Folger, N.J. 1998 T.A. Fuzzy Sets Uncertainty and Information, Prentice Hall Englewood, Cliffs.

[5] W. B. VasanthaKandasamy and Florentin Smarandache May 2004. Analysis of Social Aspects of Migrant Labourers Living with HIV /AIDS using Fuzzy theory and Neutrosophic Reference to Rural Cognitive Mapswith Special Xiquan, Phoenix, Tamilnadu in India.Published by USA

[6] W.B.VasanthaKandasamy,FlorentinSmarandache and K.Ilanthenral 2007.Elementary Fuzzy Matrix Theory and Fuzzy Models for Social Scientistis.Published by Automaton. Los Angeles. USA.

[7] Eulalia Szmidt and Janusz Kacprzyk Intuitionistic fuzzy sets- two and three term representations in the context of a Hausdorff distance, Acta Universitatis Matthiae Belii, $\quad$ series Mathematics 19 (2011) 63-62.

[8] Kosko, Bart 1986. Fuzzy Cognitive Maps, International Journals of Man -Machine Studies 34,65-75.

[9] A.Victor Devadoss and S.M.A. Shahul Hameed (March 2015) Vulnerable Attitude of Road user using Fuzzy Matrix Technique, International Journal of Engineering and Computer Science, ISSN 2319- 242,Volume 4 Issue 3, pp: 10787-10790

[10] A.Victor Devadoss and S.M.A. Shahul Hameed 2012 A Study of Attitude of Road User UsingCombined Fuzzy Cognitive Maps(CFCMs), International Journal of Computer Application Vol.59, Issue No.13, pp 39-43.

[11] A.Victor Devadoss and S.M.A. Shahul Hameed 2013 Fatigue of Driver on Roads using Combined Disjoint
Block Fuzzy Cognitive Maps (CDBFCMS) International Journal of Computer Algorithm, Vol.02, pp 201-210.

[12] A.Victor Devadoss and S.M.A. Shahul Hameed, 2013 A Study of Attitude of Road User Using in Enhancing Gross National Happiness Combined Fuzzy Cognitive Maps(CFCMs) International Journal of Data Mining Techniques and Application,Vol.2, pp.193 - 197.

[13] A.Victor Devadoss and S. Christopher 2013 A Study of Periyar Philosophy on Self Respect Using Induced Fuzzy Cognitive Maps (IFCMS),International Journal of Computer Algorithm, Vo1.2. pp 152-155.

[14] A.Victor Devadoss and A.Felix. ,2013 Fuzzy Clustering Approach to Study the Degree of Aggressiveness in Youth Violence,International Journal of Computer Algorithm, Vo1.2. pp 156-160.

[15] A.Victor Devadoss and M. Syed Ismail 2013 A Study on Religious Practices in Islam Towards Sustainable Development Using Neutrosophic Relational Maps,International Journal of Computer Algorithm, Vo1.2. pp 211-213.

[16] A.Victor Devadoss and J. Befija Minnie , A Study of Personality Influence in Building Work Life Balance Using Fuzzy Relational Maps (FRM) ,International Journal of Data Mining Techniques and Applications, Vol.02, pp.211-216

[17] Eulalia Szmidt and Janusz Kacprzyk Distance between intuitionistic fuzzy sets, Fuzzy Sets and System 114 (2000) 505-518

[18] Fred Wegman ( March 2013) Road Safety in India : A system Approach $5^{\text {th }}$ Annual Tripp Lecture. 